\title{
Beta cell function in type 1 diabetes determined from clinical and fasting biochemical variables
}

\author{
John M. Wentworth ${ }^{1,2,3} \cdot$ Naiara G. Bediaga ${ }^{1,2} \cdot$ Lynne C. Giles $^{4} \cdot$ Mario Ehlers $^{5,6} \cdot$ Stephen E. Gitelman $^{7} \cdot$ Susan Geyer $^{8}$ • \\ Carmella Evans-Molina ${ }^{9} \cdot$ Leonard C. Harrison $^{1,2} \cdot$ the Type 1 Diabetes TrialNet Study Group • the Immune Tolerance \\ Network Study Group
}

Received: 20 June 2018 / Accepted: 1 August 2018 / Published online: 30 August 2018

(C) Springer-Verlag GmbH Germany, part of Springer Nature 2018

\begin{abstract}
Aims/hypothesis Beta cell function in type 1 diabetes is commonly assessed as the average plasma C-peptide concentration over $2 \mathrm{~h}$ following a mixed-meal test $\left(\mathrm{CP}_{\mathrm{AVE}}\right)$. Monitoring of disease progression and response to disease-modifying therapy would benefit from a simpler, more convenient and less costly measure. Therefore, we determined whether $\mathrm{CP}_{\mathrm{AVE}}$ could be reliably estimated from routine clinical variables.

Methods Clinical and fasting biochemical data from eight randomised therapy trials involving participants with recently diagnosed type 1 diabetes were used to develop and validate linear models to estimate $\mathrm{CP}_{\mathrm{AVE}}$ and to test their accuracy in estimating loss of beta cell function and response to immune therapy.

Results A model based on disease duration, $\mathrm{BMI}$, insulin dose, $\mathrm{HbA}_{1 \mathrm{c}}$, fasting plasma C-peptide and fasting plasma glucose most accurately estimated loss of beta cell function (area under the receiver operating characteristic curve [AUROC] 0.89 [95\% CI $0.87,0.92]$ ) and was superior to the commonly used insulin-dose-adjusted $\mathrm{HbA}_{1 \mathrm{c}}$ (IDAA1c) measure (AUROC 0.72 [95\% CI $0.68,0.76])$. Model-estimated $\mathrm{CP}_{\mathrm{AVE}}\left(\mathrm{CP}_{\mathrm{EST}}\right)$ reliably identified treatment effects in randomised trials. $\mathrm{CP}_{\mathrm{EST}}$, compared with $\mathrm{CP}_{\mathrm{AVE}}$, required only a modest (up to $17 \%$ ) increase in sample size for equivalent statistical power.

Conclusions/interpretation $\mathrm{CP}_{\mathrm{EST}}$, approximated from six variables at a single time point, accurately identifies loss of beta cell function in type 1 diabetes and is comparable to $\mathrm{CP}_{\mathrm{AVE}}$ for identifying treatment effects. $\mathrm{CP}_{\mathrm{EST}}$ could serve as a convenient and economical measure of beta cell function in the clinic and as a primary outcome measure in trials of disease-modifying therapy in type 1 diabetes.
\end{abstract}

Keywords Adult · Beta cell function · Children · Clinical trial · Immune therapy · Immune Tolerance Network · Linear model · TrialNet · Type 1 diabetes

A list of members of the Type 1 Diabetes TrialNet Study Group and the Immune Tolerance Network Study Group can be found in the electronic supplementary material.

Electronic supplementary material The online version of this article (https://doi.org/10.1007/s00125-018-4722-z) contains peer-reviewed but unedited supplementary material, which is available to authorised users.

John M. Wentworth wentworth@wehi.edu.au

1 The Walter and Eliza Hall Institute of Medical Research, 1G Royal Parade, Parkville, VIC 3052, Australia

2 Department of Medical Biology, University of Melbourne, Parkville, VIC 3010, Australia

3 Department of Diabetes and Endocrinology, Royal Melbourne Hospital, University of Melbourne, Parkville, VIC, Australia
4 School of Public Health, The University of Adelaide, Adelaide, SA, Australia

5 Clinical Trials Group, Immune Tolerance Network, San Francisco, CA, USA

6 Present address: Eli Lilly and Company, San Diego, CA, USA

7 University of California at San Francisco, San Francisco, CA, USA

8 University of South Florida, Tampa, FL, USA

9 Indiana University School of Medicine, Indianapolis, IN, USA 


\section{Research in context}

\section{What is already known about this subject?}

- Measuring average C-peptide after a mixed meal, the gold standard measure of beta cell function in type 1 diabetes, is laborious and inconvenient

- Insulin-dose-adjusted $\mathrm{HbA}_{1 c}\left(\mathrm{IDAA}_{1 \mathrm{c}}\right)$, based on $\mathrm{HbA}_{1 \mathrm{c}}$ and insulin dose, is widely used as a simple measure of beta cell function in routine care but this measure is not accurate and is not ideal for assessing responses to disease-modifying therapy

\section{What is the key question?}

- Can a more accurate measure of beta cell function in type 1 diabetes be developed from routine clinical measures?

\section{What are the new findings?}

- Estimated C-peptide (CPEST), based on six routine measures, accurately identifies significant loss of beta cell function and reliably identifies treatment effects in randomised trials of immune therapy for type 1 diabetes

- $\mathrm{CP}_{\mathrm{EST}}$ is more accurate than IDAA1c

\section{How might this impact on clinical practice in the foreseeable future?}

- CPEST could serve as a simple measure of beta cell function in routine practice and as a more economical and acceptable primary outcome measure in future trials of disease-modifying therapy

$\begin{array}{ll}\text { Abbreviations } \\ \text { AIC } & \text { Akaike's information criterion } \\ \text { AUROC } & \text { Area under the ROC curve } \\ \mathrm{CP}_{\mathrm{AVE}} & \begin{array}{l}\text { Average plasma C-peptide concentration over } 2 \mathrm{~h} \\ \text { following a mixed-meal test }\end{array} \\ & \text { Estimated } \mathrm{CP}_{\mathrm{AVE}} \\ \mathrm{CP}_{\mathrm{EST}} & \text { Fasting C-peptide } \\ \mathrm{FCP} & \text { Fasting plasma glucose } \\ \mathrm{FPG} & \text { Insulin-dose-adjusted } \mathrm{HbA}_{1 \mathrm{c}} \\ \mathrm{IDAA} 1 \mathrm{c} & \text { Immune Tolerance Network } \\ \text { ITN } & \text { Receiver operating characteristic } \\ \text { ROC } & \text { R }\end{array}$

\section{Introduction}

Therapies targeting pancreatic islet autoimmunity are being tested for their ability to preserve insulin-secreting beta cells and modify the natural history of type 1 diabetes after diagnosis [1]. The widely accepted measure of their efficacy is the average plasma $\mathrm{C}$-peptide concentration over $2 \mathrm{~h}$ following a mixed-meal test $\left(\mathrm{CP}_{\mathrm{AVE}}\right)$ [2]. However, the measurement of $\mathrm{CP}_{\mathrm{AVE}}$ requires ingestion of a liquid meal and collection of at least seven venous blood samples. A more convenient measure would streamline the assessment of beta cell function, particularly when disease-modifying therapies enter routine clinical practice.

In clinical trials, the biological agents rituximab, teplizumab and abatacept have been shown to improve beta cell function for at least 1 year in people with recently diagnosed type 1 diabetes [3-5]. Improved $\mathrm{CP}_{\mathrm{AVE}}$ in these trials was associated with a decrease in insulin requirement and in $\mathrm{HbA}_{1 \mathrm{c}}$, suggesting that these routine clinical measures may be useful surrogates of beta cell function. Indeed, insulin dosage and $\mathrm{HbA}_{1 \mathrm{c}}$ are used to calculate insulin-dose-adjusted $\mathrm{HbA}_{1 \mathrm{c}}$ (IDAA1c), which identifies type 1 diabetes in children with residual beta cell function $[6,7]$. Other studies in children and adults at high risk of developing type 1 diabetes have shown that $\mathrm{HbA}_{1 \mathrm{c}}$, age and BMI correlate with the C-peptide response to oral glucose [8-10], again suggesting that these routine measures could serve as useful surrogates of beta cell function in the clinic.

We aimed to develop a simple and reliable model that could accurately estimate $\mathrm{CP}_{\mathrm{AVE}}$, based on a combination of routine clinical measures and fasting C-peptide (FCP) plasma levels. Data from eight trials involving people with recently diagnosed type 1 diabetes [3, 4, 11-16] were used to build predictive models to approximate $\mathrm{CP}_{\mathrm{AVE}}$ and derive estimates of variability for use in future trial design.

\section{Methods}

Data collection Study participants gave informed consent if adult and assent if aged under 18 years. All studies were approved by the responsible ethics committee and were carried out in accordance with the Declaration of Helsinki as revised in 2008. Clinical and biochemical data from the TrialNet TN02, TN-05, TN-08, TN-09 and TN-14 clinical trials (Table 1) $[3,11-13]$ were extracted from the TrialNet data repository in April 2014. In all of these trials, predominantly white participants were assessed at 0, 3, 6 and 12 months after enrolment 


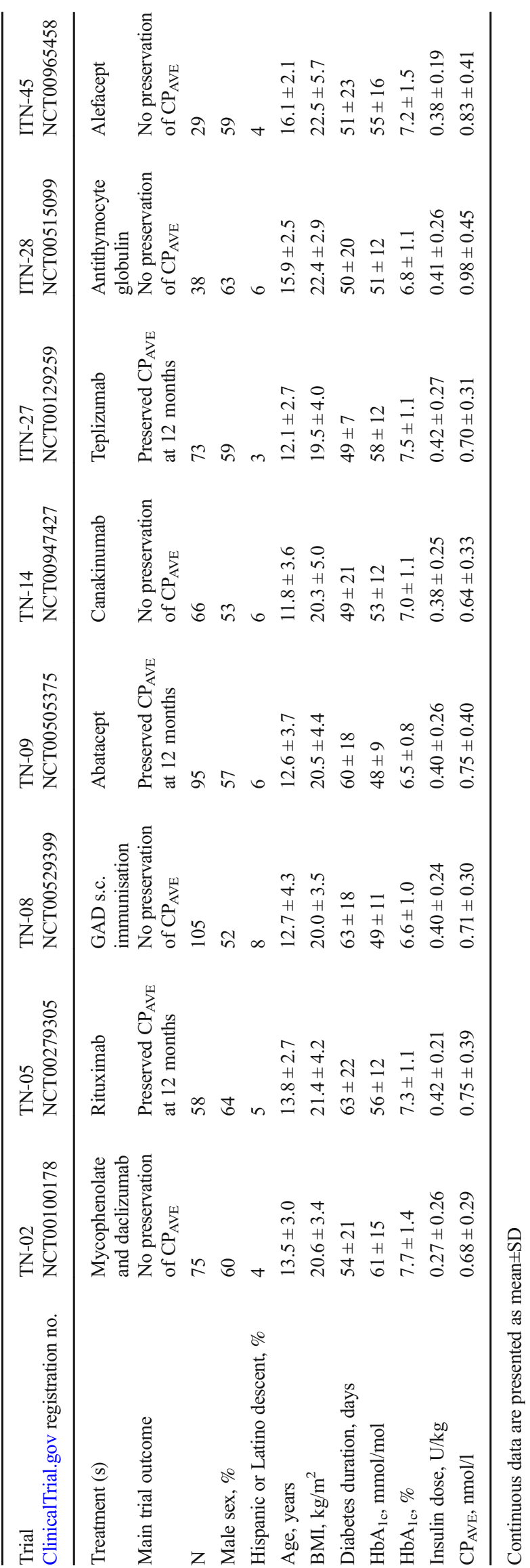


and, for TN-08 and TN-14, also at 9 months. Additional data from the Immune Tolerance Network (ITN)-27, ITN-28 and ITN-45 trials [14-16] were extracted in February 2016 and comprised clinical and biochemical measures obtained at the 0, 6 and 12 month time points. Data from Australian adults participating in an ongoing clinical trial of empagliflozin in recently diagnosed type 1 diabetes (Australian New Zealand Clinical Trials Registry [www.anzctr.org.au] registration no. ACTRN12617000016336) were obtained in April 2018. Plasma C-peptide concentrations in TrialNet and ITN trials were determined to sensitivities of 0.017 and $0.05 \mathrm{nmol} / 1$ with TOSOH 2000 and TOSOH 1800 autoanalysers (TOSOH, South San Francisco, CA, USA), respectively. In Australia, $\mathrm{C}$-peptide and $\mathrm{HbA}_{1 \mathrm{c}}$ were measured by Melbourne Health Pathology (Parkville, VIC, Australia) using ARCHITECT (Abbott, Wiesbaden, Germany) and Ultra ${ }^{2}$ (Primus Diagnostics, Kansas City, MO, USA) kits, respectively.

After receipt of the archived data, missing weight, height, insulin dose and $\mathrm{HbA}_{1 \mathrm{c}}$ values were imputed where possible by filling backwards or forwards from the nearest time point (if within 1 month) or by averaging values either side of the missing value. Undetectable C-peptide concentrations observed in TrialNet and ITN datasets were assigned values of half of the lower limit of detection. Because daily insulin requirements are $\sim 20 \%$ lower with insulin pump therapy than with injection therapy [17], the daily insulin dose of TrialNet participants who reported using insulin pumps was multiplied by 1.25 .

Analyses Correlation and receiver operating characteristic (ROC) curve analyses were performed using Prism software (v6.0g for Mac; GraphPad, San Diego, CA, USA). Data modelling was performed using R software v3.3.2 (www.rproject.org). Half of the participants aged $<21$ years at baseline were randomly assigned to train the Linear Mixed Models to determine the estimated $\mathrm{CP}_{\mathrm{AVE}}\left(\mathrm{CP}_{\mathrm{EST}}\right)$; a validation dataset, comprising data from the remaining participants aged $<21$ years at baseline, was used to identify the best models. $\mathrm{CP}_{\mathrm{AVE}}$ was $\log _{e}$-transformed after adding 1 [18] and eight covariates were chosen for inclusion in the prediction model: age, sex, BMI, diabetes duration, insulin dose per kg body weight, FCP, fasting plasma glucose (FPG) and $\mathrm{HbA}_{1 \mathrm{c}}$. Participant identification no. was added as a random effect to account for the repeated measurements from the same individual. The 'dredge' function in the MuMIn library (v1.15.6; www.r-project.org) was used to construct 256 models from all possible combinations of variables and these models were ranked by Akaike's information criterion (AIC), corrected for a finite sample size. To validate the rankings of the models, the 'lmer' function in the lme4 library (v1.1-13; www.r-project.org) was used to rebuild the models in the validation dataset based on the relevant inputs, thereby enabling their AIC values to be determined. To compare treatment arms of clinical trials, mixed models were fitted using 'Imer' with a random intercept per participant and adjusted for sex, age and baseline $\log _{e}\left(\mathrm{CP}_{\mathrm{AVE}}+1\right)$ or $\log _{e}\left(\mathrm{CP}_{\mathrm{EST}}+1\right)$. The lmer-Test package was used to calculate $p$ values based on $\mathrm{F}$ statistics for treatment comparisons.

Power calculations for the comparison of two groups with equal variance were performed using placebo-group data from the validation dataset and Stata (v14.2) software (StataCorp, College Station, TX, USA). They were based on the mean and $\mathrm{SD}$ of the $\log _{e}\left(\mathrm{CP}_{\mathrm{AVE}}+1\right)$ values and a conservative approximation of the $\mathrm{SD}$ of $\log _{e}\left(\mathrm{CP}_{\mathrm{EST}}+1\right)$ values, calculated by combining the variance of $\log _{\mathrm{e}}\left(\mathrm{CP}_{\mathrm{AVE}}+1\right)$ values with an estimated variance of the difference between the $\log _{e}$ $\left(\mathrm{CP}_{\mathrm{AVE}}+1\right)$ and $\log _{e}\left(\mathrm{CP}_{\mathrm{EST}}+1\right)$ values according to the following formula:

$\mathrm{SD}_{\mathrm{APPROX}}=\sqrt{ }\left(\sigma^{2} \log _{e}\left(\mathrm{CP}_{\mathrm{AVE}}+1\right)+\sigma^{2} \log _{e}\left(\mathrm{CP}_{\mathrm{AVE}}+1\right)-\log _{e}\left(\mathrm{CP}_{\mathrm{EST}}+1\right)\right)$

A standard trial design that assumed a treatment effect of $50 \%$ increase in $\log _{\mathrm{e}}\left(\mathrm{CP}_{\mathrm{AVE}}+1\right)$ at 12 months, two-tailed $\alpha=$ 0.05 , power $=0.8$ and 2:1 (active: placebo) randomisation was used to estimate the required number of participants.

\section{Results}

Developing and validating equations to estimate beta cell function The baseline characteristics of participants whose data were used to develop the models are presented according to clinical trial and treatment assignment in Table 1. Initially, we used data from participants aged $<21$ years to fit and test linear models for three reasons: (1) this age group accounts for over $75 \%$ of classic type 1 diabetes presentations [19]; (2) beta cell function declines more slowly in older people $[20,21]$ and (3) preservation of beta cell function is more characteristic of younger participants in trials of biological agents [22]. Half of the participants were randomly assigned to train linear models to estimate $\mathrm{CP}_{\mathrm{AVE}}$ using one or more of the eight input variables of age, sex, BMI, diabetes duration, insulin dose $/ \mathrm{kg}$ body weight, FCP, FPG and $\mathrm{HbA}_{1 \mathrm{c}}$. Based on one to eight predictor variables, the AIC value was used to identify the most accurate models, hereafter referred to as M1-M8. The coefficients and associated standard errors of the variables included in the eight models are provided in electronic supplementary material (ESM) Table 1. Data from the remaining half of the participants were used to validate the models. M6, which is based on BMI, diabetes duration, insulin dose $/ \mathrm{kg}$ body weight, FCP, FPG and $\mathrm{HbA}_{1 \mathrm{c}}$, was chosen for subsequent testing because its AIC value was lowest in the validation dataset (Fig. 1). Within the validation dataset, M6modelled $\mathrm{CP}_{\mathrm{AVE}}$ (hereafter called $\mathrm{CP}_{\mathrm{EST}}$ ) and observed 
Fig. 1 Performance characteristics of eight models to estimate $\log _{e}\left(\mathrm{CP}_{\mathrm{AVE}}+1\right)$ from single time point data. The components of each model are indicated below the graph of the AIC value against the number of model variables in the context of the validation dataset. M6 was used to calculate $\mathrm{CP}_{\mathrm{EST}}$ values. T1D, type 1 diabetes

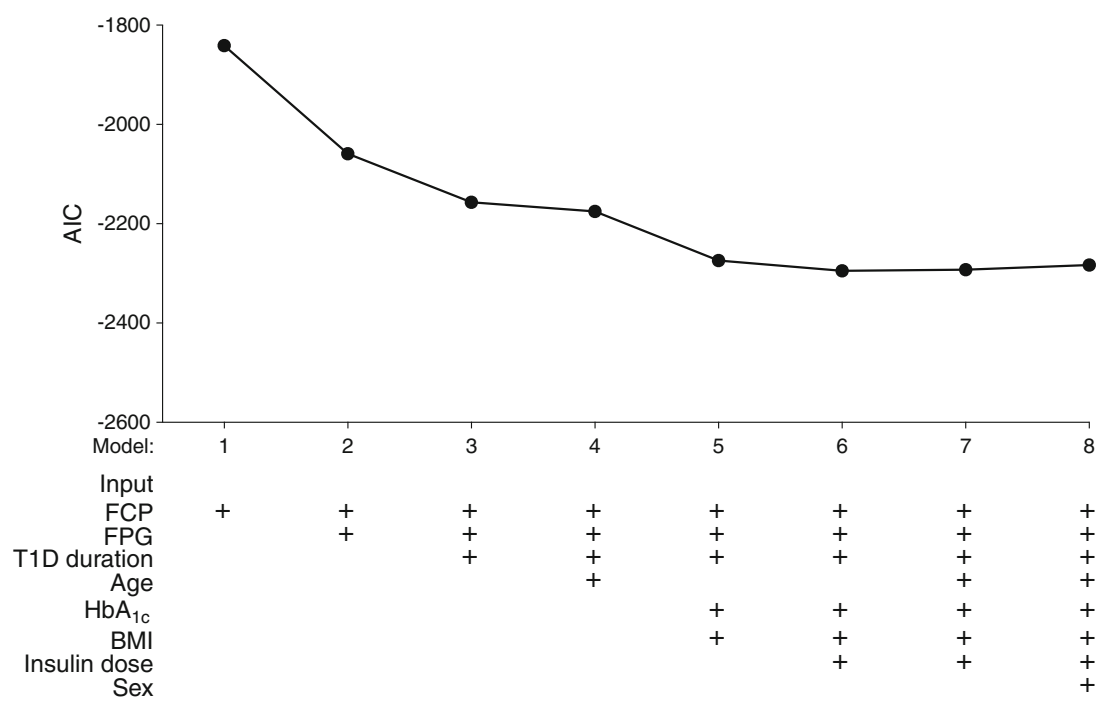

$\mathrm{CP}_{\mathrm{AVE}}$ were strongly correlated $\left(r^{2}=0.816, p<0.001\right)$. The equation for $\mathrm{M} 6$ is:

$\log _{e}\left(\mathrm{CP}_{\mathrm{EST}}+1\right)=0.317+0.00956 \times \mathrm{BMI}-0.000159 \times$ duration $+0.710 \times \mathrm{FCP}-0.0117 \times \mathrm{FPG}-0.0186 \times \mathrm{HbA}_{1 \mathrm{c}}-$ $0.0665 \times$ insulin (ESM Methods), where BMI is in $\mathrm{kg} / \mathrm{m}^{2}$, duration is in days, FCP is in $\mathrm{nmol} / \mathrm{l}, \mathrm{FPG}$ is in $\mathrm{mmol} / \mathrm{l}$, $\mathrm{HbA}_{1 \mathrm{c}}$ is in \% and insulin is in $\mathrm{U} / \mathrm{kg}$.

Because M6 did not require age as an input, we determined whether it might also be accurate in the 150 trial participants aged $>21$ years whose data were not included in either the training dataset or the validation dataset (baseline characteristics are presented in ESM Table 2). Correlation analysis of data from 554 meal tests performed during the first trial year again demonstrated a strong correlation between $\mathrm{CP}_{\mathrm{AVE}}$ and $\mathrm{CP}_{\mathrm{EST}}\left(r^{2}=0.729, p<0.001\right)$. Strong agreement between $\mathrm{CP}_{\mathrm{AVE}}$ and $\mathrm{CP}_{\mathrm{EST}}\left(r^{2}=0.869, p<0.001\right)$ was also observed when M6 was applied to data from 31 meal tests from ten participants (three female sex, seven male sex, aged 18-37 years at diagnosis; ESM Table 3) in an ongoing Australian trial of empagliflozin in recently diagnosed type 1 diabetes.

Applying $\mathrm{CP}_{\mathrm{EST}}$ to clinical practice $\mathrm{ROC}$ curve analysis of the validation dataset was performed to determine how accurately $\mathrm{CP}_{\mathrm{EST}}$ identified significant loss of beta cell function at 3,6 and 12 months after clinical trial entry, defined as a decrease of $7.5 \%$ or more of the baseline $\mathrm{CP}_{\mathrm{AVE}}[20,23]$. The ROC curves (Fig. 2) show areas under the curve ranging from $0.86(95 \%$ CI $0.81,0.91)$ to $0.91(95 \%$ CI $0.87,0.95)$. When tested for the ability to identify significant loss of beta cell function at 3,6 and 12 months compared with baseline, $\mathrm{CP}_{\mathrm{EST}}$ furnished an area under the ROC (AUROC) of 0.89 (95\% CI 0.87, 0.92). The corresponding AUROC for trial participants aged $>21$ years was 0.88 (95\% CI 0.84, 0.91). We also determined how accurately IDAA1c, an extant clinical measure of beta cell function [6], identified trial participants who had lost significant beta cell function. The AUROC of the ratio of baseline to 3,6 and 12 month IDAA1c was markedly lower at 0.72 (95\% CI 0.68, 0.76).

Implications for clinical trial design The potential suitability of $\mathrm{CP}_{\mathrm{EST}}$ as an alternative primary outcome measure for clinical
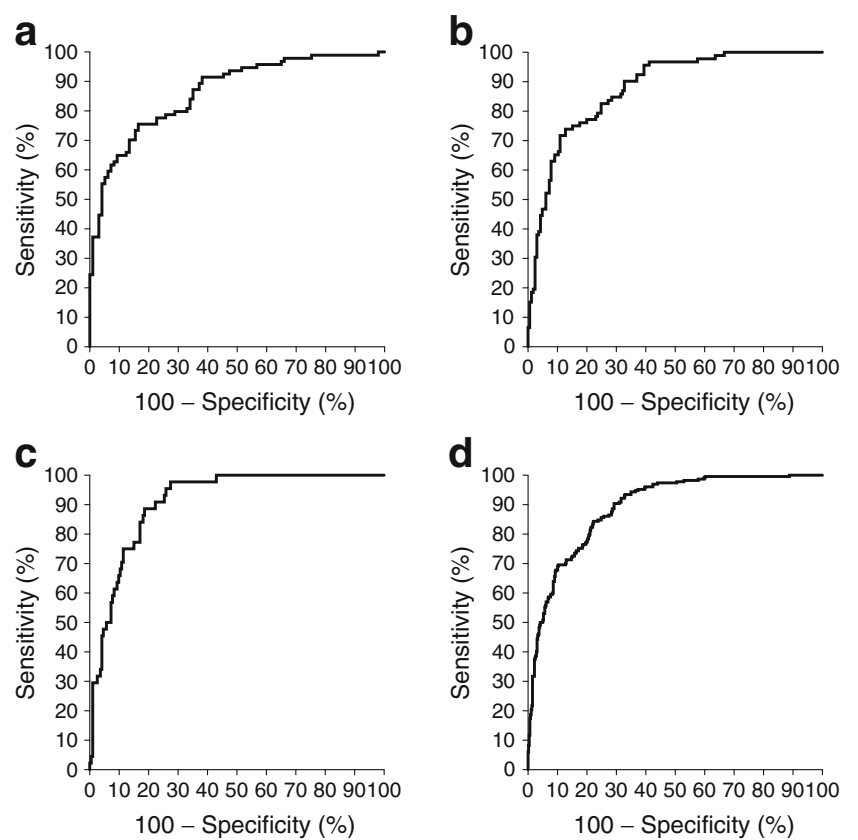

Fig. 2 (a-c) ROC curve analysis was used to determine how accurately $\mathrm{CP}_{\mathrm{EST}}$ identified participants whose $\mathrm{CP}_{\mathrm{AVE}}$ decreased by more than $7.5 \%$ of the baseline value at $3(\mathbf{a}), 6(\mathbf{b})$ and 12 (c) months after clinical trial entry. (d) ROC curve analysis for the participants with a $7.5 \%$ decrease of $\mathrm{CP}_{\mathrm{AVE}}$ at 3,6 and 12 months. The AUROC $(95 \% \mathrm{CI})$ was $0.86(0.81$, $0.91), 0.88(0.84,0.92), 0.91(0.87,0.95)$ and $0.89(0.87,0.92)$ for $(\mathbf{a}-\mathbf{d})$, respectively. These analyses used the validation dataset, which was derived from half of the participant population and was fully independent of the dataset used to develop the $\mathrm{CP}_{\mathrm{EST}}$ model 
trials was then assessed. All available data from participants (children and adults) in the TN-05 rituximab [4], TN-09 abatacept [3] and ITN-27 teplizumab [15] trials were analysed. The major conclusion from each trial, that the active therapy preserved beta cell function over the first year after diagnosis, held regardless of whether $\mathrm{CP}_{\mathrm{AVE}}$ or $\mathrm{CP}_{\mathrm{EST}}$ was used to compare treatment groups (Fig. 3). We also applied $\mathrm{CP}_{\mathrm{EST}}$ to data from the other five negative trials and observed similar treatment effects (ESM Fig. 1).

To examine implications for clinical trial design, the SD of $\log _{e}\left(\mathrm{CP}_{\mathrm{EST}}+1\right)$ values was conservatively estimated by combining the variance of $\log _{e}\left(\mathrm{CP}_{\mathrm{AVE}}+1\right)$ values with the variance of the difference between the $\log _{e}\left(\mathrm{CP}_{\mathrm{AVE}}+1\right)$ and $\log _{e}$ $\left(\mathrm{CP}_{\mathrm{EST}}+1\right)$ values, as outlined in Methods. Using 12 month placebo-group data from the validation dataset from participants aged $<21$ years, the mean $\pm \mathrm{SD}$ of $\log _{e}\left(\mathrm{CP}_{\mathrm{AVE}}+1\right)$ and $\log _{e}\left(\mathrm{CP}_{\mathrm{EST}}+1\right)$ was $0.320 \pm 0.218$ and $0.331 \pm 0.166$, respectively. The variance of the difference between these values was 0.0087 , resulting in an estimated SD for $\log _{e}\left(\mathrm{CP}_{\mathrm{EST}}+\right.$ 1) of 0.237. When the $\log _{e}\left(\mathrm{CP}_{\mathrm{AVE}}+1\right)$ mean $\pm \mathrm{SD}$ and the estimated $\mathrm{SD}$ for $\log _{e}\left(\mathrm{CP}_{\mathrm{EST}}+1\right)$ were applied to a standard trial design that assumed a treatment effect of $50 \%$ increase in $\log _{\mathrm{e}}\left(\mathrm{CP}_{\mathrm{AVE}}+1\right)$ at 12 months (i.e. $\left.\Delta=0.160\right)$, two-tailed $\alpha=$ 0.05 and 2:1 (active: placebo) randomisation, the number of participants required to achieve $80 \%$ power was 69 for $\log _{e}$ $\left(\mathrm{CP}_{\mathrm{AVE}}+1\right)$ and 81 for $\log _{e}\left(\mathrm{CP}_{\mathrm{EST}}+1\right)$ (i.e. $17 \%$ higher). When the validation data were combined with placebogroup data from adult participants aged $>21$ years (combined dataset), the mean $\pm \mathrm{SD}$ for $\log _{e}\left(\mathrm{CP}_{\mathrm{AVE}}+1\right)$ and $\log _{e}\left(\mathrm{CP}_{\mathrm{EST}}+\right.$ 1) increased to $0.370 \pm 0.227$ and $0.377 \pm 0.174$, respectively, and the estimated SD for $\log _{e}\left(\mathrm{CP}_{\mathrm{EST}}+1\right)$ increased to 0.247 , yielding $\Delta=0.185$ and a requirement for 57 participants if $\log _{e}\left(\mathrm{CP}_{\mathrm{AVE}}+1\right)$ was the primary outcome measure and 66 (i.e. $16 \%$ higher), if $\log _{e}\left(\mathrm{CP}_{\mathrm{EST}}+1\right)$ was used. If geometric means for $\log _{e}\left(\mathrm{CP}_{\mathrm{AVE}}+1\right)$ were instead used as the basis for power calculations, the use of $\log _{e}\left(\mathrm{CP}_{\mathrm{EST}}+1\right)$ as the primary outcome measure required $17 \%$ and $13 \%$ more participants, respectively, in the context of the validation dataset and combined dataset.

\section{Discussion}

Using six, single time point measures, we describe a model $\left(\mathrm{CP}_{\mathrm{EST}}\right)$ for estimating $\mathrm{CP}_{\mathrm{AVE}}$ that reliably identifies loss of beta cell function in children and adults with recently diagnosed type 1 diabetes. The accuracy of $\mathrm{CP}_{\mathrm{EST}}$ was comparable with that of $\mathrm{CP}_{\mathrm{AVE}}$ and superior to that of IDAA1c. When applied to data from the active and placebo treatment arms of three trials of immune modulators that preserved beta cell function, $\mathrm{CP}_{\mathrm{EST}}$ identified differences in beta cell function over the first year that were similar to those identified using $\mathrm{CP}_{\mathrm{AVE}}$. These findings reinforce the strong correlation between FCP and $\mathrm{CP}_{\mathrm{AVE}}$ in people with recently diagnosed type 1 diabetes $[8,20]$ and suggest that the relatively simple biochemical measurements of $\mathrm{HbA}_{1 \mathrm{c}}, \mathrm{FCP}$ and FPG combined
Fig. 3 Outcomes of TN-05 (rituximab), TN-09 (abatacept) and ITN-27 (teplizumab) trials according to $\mathrm{CP}_{\mathrm{AVE}}$ and $\mathrm{CP}_{\mathrm{EST}}$. Outcomes for participants receiving active (black circles) and placebo (white squares) treatment in TN-05 (a, b; 51 active and 29 placebo participants), TN-09 (c, d; 74 active and 31 placebo participants) and ITN-27 (e, f; 54 active and 25 placebo participants) are shown as means \pm SEM. $\mathrm{CP}_{\mathrm{AVE}}$ measured by meal test is presented in $(\mathbf{a}, \mathbf{c}, \mathbf{e})$ and $\mathrm{CP}_{\mathrm{EST}}$ measured from single time point measures is presented in (b, d, f). Differences between treatment groups across all time points after baseline were determined using a mixed model that corrects for baseline $\mathrm{CP}_{\mathrm{AVE}}$, age and sex $(\mathbf{a}, \mathbf{c}, \mathbf{e})$ or $\mathrm{CP}_{\mathrm{EST}}$, age and $\operatorname{sex}(\mathbf{b}, \mathbf{d}, \mathbf{f}) .{ }^{*} p<0.05$, $* * p<0.01$ and $* * * p<0.001$ for differences between treatment groups
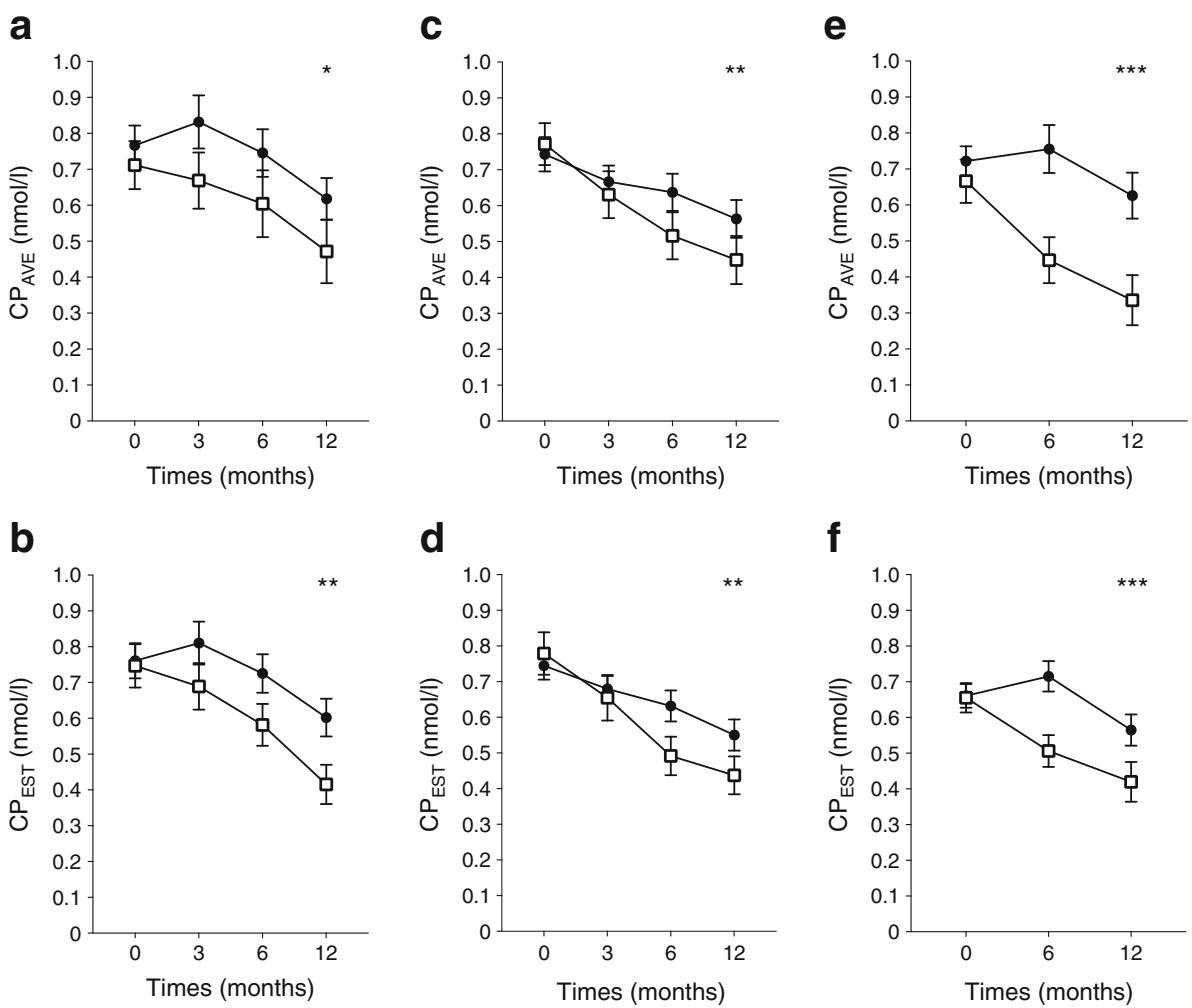
with BMI, insulin dose and disease duration may be sufficient to assess an individual's response to disease-modifying therapy.

$\mathrm{CP}_{\mathrm{EST}}$ did not require age as an input despite the known strong association of age with beta cell function and with its rate of decline following diagnosis [20, 24]. Whereas age was an input for M4, it was not used in the optimal models that incorporated five or six inputs and which instead used $\mathrm{HbA}_{1 \mathrm{c}}$, BMI and insulin dose. Clearly these other clinical measures accounted for the effect of age on beta cell function. During model development with the training dataset, using age as an input did not always increase accuracy. For example, of the eight models based on four inputs that were more accurate than M3, only two (including M4) included age as an input. Similarly, of the six models based on five inputs that were more accurate than M4, only three used age.

Power calculations, based on a conservative estimate of the $\mathrm{SD}$ of $\log _{e}\left(\mathrm{CP}_{\mathrm{EST}}+1\right)$, indicated that sample size would need to increase by up to $17 \%$ if $\mathrm{CP}_{\mathrm{EST}}$ was used as a primary outcome measure. However, because the SD of $\log _{e}$ $\left(\mathrm{CP}_{\mathrm{EST}}+1\right)$ was lower than the $\mathrm{SD}$ of $\log _{e}\left(\mathrm{CP}_{\mathrm{AVE}}+1\right)$, it is possible that modelled values are inherently less variable and therefore more accurate measures of beta cell function. This might be explained by the fact that a single fasting test eliminates variation attributable to meal ingestion and multiple sampling. Alternatively, incorporation of FPG into the model may account for day-to-day variation in insulin sensitivity [25], which in turn could alter beta cell function [26] and increase $\mathrm{CP}_{\mathrm{AVE}}$ variability between meal tests. It will be important to establish the power of $\mathrm{CP}_{\mathrm{EST}}$ relative to $\mathrm{CP}_{\mathrm{AVE}}$ in future trials because $\mathrm{CP}_{\mathrm{EST}}$ is simpler and much more convenient. Even if subsequent testing shows that using $\mathrm{CP}_{\mathrm{EST}}$ would require a modest increase in sample size, this would need to be balanced against its potential to improve participant recruitment and satisfaction. $\mathrm{CP}_{\mathrm{EST}}$ also enables more frequent assessment of beta cell function during a trial and obviates the need to admit participants to a clinical trials unit for a meal test, thereby reducing trial costs.

In the clinical setting, the ability of $\mathrm{CP}_{\mathrm{EST}}$ to identify individuals who lose beta cell function commends it for routine use in monitoring an individual's beta cell function over time and determining their response to disease-modifying therapy. $\mathrm{CP}_{\mathrm{EST}}$ is also likely to be useful for larger Phase 3 and 4 trials, and for studies of type 1 diabetes cohorts that aim to identify factors associated with disease progression and the relationship between C-peptide preservation and long-term complications such as hypoglycaemia unawareness and rates of microand macrovascular disease.

IDAA1c is a measure of beta cell function that has gained acceptance in clinical practice because it reliably identifies children with type 1 diabetes who have substantial beta cell reserve, defined as a peak plasma C-peptide response to a mixed meal of greater than $0.3 \mathrm{nmol} / 1(0.9 \mathrm{ng} / \mathrm{ml})[6,7]$.
However, our analysis shows that IDAA1c has relatively poor accuracy for diagnosing significant loss of beta cell function, in accord with an earlier study which showed that IDAA1c was not a reliable surrogate of $\mathrm{CP}_{\mathrm{AVE}}$ during the first 4 years following the diagnosis of type 1 diabetes [21]. Therefore, compared with modelled $\mathrm{CP}_{\mathrm{EST}}$, IDAA1c is not suitable for assessing disease-modifying therapy.

Last, several caveats are in order. Our cohort comprised participants who were mostly of European descent and had type 1 diabetes for no more than 100 days when $\mathrm{CP}_{\mathrm{AVE}}$ was first measured. Therefore, the accuracy of our model in other ethnic groups or in those with longer-standing type 1 diabetes is uncertain. In addition, despite the model's accuracy in the two adult populations tested, caution should be exercised in applying it to other adult populations until its accuracy is further confirmed. Finally, because FCP and $\mathrm{HbA}_{1 \mathrm{c}}$ were measured at only three laboratories, the generalisability of $\mathrm{CP}_{\mathrm{EST}}$ should be determined in the context of other laboratories and assay platforms.

In summary, $\mathrm{CP}_{\mathrm{EST}}$ modelled from six routine clinical and biochemical variables is an accurate measure of beta cell function in children and young adults with recently diagnosed type 1 diabetes. The simplicity and convenience of $\mathrm{CP}_{\mathrm{EST}}$ combined with its superior accuracy when compared with IDAA1c argues for its implementation and further validation in assessing beta cell function in clinical trials and during the course of routine clinical care.

Acknowledgements We are grateful to the trial participants and to $\mathrm{M}$. Ritchie (Molecular Medicine Division, Walter and Eliza Hall Institute, Australia) and A. Gorelik (Epicentre, Royal Melbourne Hospital, Australia) for statistical advice. We also thank the ITN and TrialNet investigators who contributed to original data, listed in the ESM.

Data availability Data used for this study can be accessed by application through the TrialNet (www.trialnet.org) and Immune Tolerance Network (www.immunetolerance.org) websites.

Funding This work was supported by JDRF Australia (Clinical Practitioner Fellowship to JMW) and JDRF (Strategic Research Agreement to CE-M) and the Australian National Health and Medical Research Council (NHMRC) (Program Grant 1037321 to LCH and CRE 1078106 Fellowship to JMW). LCH is a Senior Principal Research Fellow of the NHMRC. This work was made possible through Victorian State Government Operational Infrastructure Support and Australian National Health and Medical Research Council Research Institute Infrastructure Support Scheme. This manuscript includes clinical and biochemical data provided by the TrialNet data repository from clinical trials $\mathrm{TN}-02, \mathrm{TN}-05, \mathrm{TN}-08, \mathrm{TN}-09$ and $\mathrm{TN}-14$. TrialNet is currently funded by NIH grants U01 DK061010, U01 DK061034, U01 DK061042, U01 DK061058, U01 DK085461, U01 DK085465, U01 DK085466, U01 DK085476, U01 DK085499, U01 DK085509, U01 DK103180, U01 DK103153, U01 DK103266, U01 DK103282, U01 DK106984, U01 DK106994, U01 DK107013, U01 DK107014, UC4 DK106993, and the JDRF. Research reported in this publication was also performed as a project of the Immune Tolerance Network and was supported by the National Institute of Diabetes and Digestive and Kidney Diseases (NIDDK) and the National Institute of Allergy and Infectious Diseases (NIAID) of the National Institutes of Health under Award 
Number UM1AI109565. The content is solely the responsibility of the authors and does not necessarily represent the official views of the National Institutes of Health. The funding sources had no role in the writing of the manuscript or the decision to submit it for publication.

Duality of interest SEG received funding from the Immune Tolerance Network (in turn funded by NIAID) for his role as principal investigator of the START trial (ITN-28). SG received a grant from NIDDK for unrelated work. All other authors declare that there is no duality of interest associated with their contribution to this manuscript.

Contribution statement JMW devised the study. JMW, NGB, LCG and $\mathrm{LCH}$ analysed the data and prepared the manuscript. All named authors contributed to collection, collation, analysis and interpretation of the data, helped to revise the manuscript and approved it for publication. Authors listed in the ESM contributed by performing the TrialNet and ITN clinical trials. JMW is the guarantor and takes full responsibility for the work as a whole, including the study design, access to data and the decision to submit and publish the manuscript.

\section{References}

1. Skyler JS (2013) Primary and secondary prevention of type 1 diabetes. Diabet Med 30:161-169

2. Greenbaum CJ, Mandrup-Poulsen T, McGee PF et al (2008) Mixed-meal tolerance test versus glucagon stimulation test for the assessment of $\beta$-cell function in therapeutic trials in type 1 diabetes. Diabetes Care 31:1966-1971

3. Orban T, Bundy B, Becker DJ et al (2011) Co-stimulation modulation with abatacept in patients with recent-onset type 1 diabetes: a randomised, double-blind, placebo-controlled trial. Lancet 378: 412-419

4. Pescovitz MD, Greenbaum CJ, Krause-Steinrauf H et al (2009) Rituximab, B-lymphocyte depletion, and preservation of beta-cell function. N Engl J Med 361:2143-2152

5. Sherry N, Hagopian W, Ludvigsson J et al (2011) Teplizumab for treatment of type 1 diabetes (Protege study): 1-year results from a randomised, placebo-controlled trial. Lancet 378:487-497

6. Mortensen HB, Hougaard P, Swift P et al (2009) New definition for the partial remission period in children and adolescents with type 1 diabetes. Diabetes Care 32:1384-1390

7. Max Andersen ML, Hougaard P, Porksen S et al (2014) Partial remission definition: validation based on the insulin dose-adjusted HbA1c (IDAA1C) in 129 Danish children with new-onset type 1 diabetes. Pediatr Diabetes 15:469-476

8. Sosenko JM, Krischer JP, Palmer JP et al (2008) A risk score for type 1 diabetes derived from autoantibody-positive participants in the diabetes prevention trial-type 1. Diabetes Care 31:528-533

9. Sosenko JM, Skyler JS, Palmer JP et al (2013) The prediction of type 1 diabetes by multiple autoantibody levels and their incorporation into an autoantibody risk score in relatives of type 1 diabetic patients. Diabetes Care 36:2615-2620

10. Sosenko JM, Geyer S, Skyler JS et al (2017) The influence of body mass index and age on C-peptide at the diagnosis of type 1 diabetes in children who participated in the diabetes prevention trial-type 1 . Pediatr Diabetes 19:403-409

11. Gottlieb PA, Quinlan S, Krause-Steinrauf H et al (2010) Failure to preserve $\beta$-cell function with mycophenolate mofetil and daclizumab combined therapy in patients with new- onset type 1 diabetes. Diabetes Care 33:826-832

12. Wherrett DK, Bundy B, Becker DJ et al (2011) Antigen-based therapy with glutamic acid decarboxylase (GAD) vaccine in patients with recent-onset type 1 diabetes: a randomised doubleblind trial. Lancet 378:319-327

13. Moran A, Bundy B, Becker DJ et al (2013) Interleukin-1 antagonism in type 1 diabetes of recent onset: two multicentre, randomised, double-blind, placebo-controlled trials. Lancet 381: 1905-1915

14. Gitelman SE, Gottlieb PA, Rigby MR et al (2013) Antithymocyte globulin treatment for patients with recent-onset type 1 diabetes: 12-month results of a randomised, placebo-controlled, phase 2 trial. Lancet Diabetes Endocrinol 1:306-316

15. Herold KC, Gitelman SE, Ehlers MR et al (2013) Teplizumab (anti$\mathrm{CD} 3 \mathrm{mAb}$ ) treatment preserves $\mathrm{C}$-peptide responses in patients with new-onset type 1 diabetes in a randomized controlled trial: metabolic and immunologic features at baseline identify a subgroup of responders. Diabetes 62:3766-3774

16. Rigby MR, DiMeglio LA, Rendell MS et al (2013) Targeting of memory $\mathrm{T}$ cells with alefacept in new-onset type 1 diabetes (T1DAL study): 12 month results of a randomised, double-blind, placebo-controlled phase 2 trial. Lancet Diabetes Endocrinol 1: 284-294

17. Pickup JC (2012) Insulin-pump therapy for type 1 diabetes mellitus. N Engl J Med 366:1616-1624

18. Bundy BN, Krischer JP, Type 1 Diabetes TrialNet Study Group (2016) A model-based approach to sample size estimation in recent onset type 1 diabetes. Diabetes Metab Res Rev 32:827-834

19. Beck RW, Tamborlane WV, Bergenstal RM et al (2012) The T1D Exchange clinic registry. J Clin Endocrinol Metab 97:4383-4389

20. Greenbaum CJ, Beam CA, Boulware D et al (2012) Fall in Cpeptide during first 2 years from diagnosis: evidence of at least two distinct phases from composite Type 1 Diabetes TrialNet data. Diabetes 61:2066-2073

21. Hao W, Gitelman S, DiMeglio LA, Boulware D, Greenbaum CJ, Type 1 Diabetes TrialNet Study Group (2016) Fall in C-peptide during first 4 years from diagnosis of type 1 diabetes: variable relation to age, HbA1c, and insulin dose. Diabetes Care 39:1664 1670

22. Wherrett DK, Chiang JL, Delamater AM et al (2015) Defining pathways for development of disease-modifying therapies in children with type 1 diabetes: a consensus report. Diabetes Care 38: 1975-1985

23. Herold KC, Gitelman SE, Masharani U et al (2005) A single course of anti-CD3 monoclonal antibody hOKT3gamma1(Ala-Ala) results in improvement in C-peptide responses and clinical parameters for at least 2 years after onset of type 1 diabetes. Diabetes 54:17631769

24. Barker A, Lauria A, Schloot N et al (2014) Age-dependent decline of $\beta$-cell function in type 1 diabetes after diagnosis: a multi-centre longitudinal study. Diabetes Obes Metab 16:262-267

25. Moberg E, Kollind M, Lins PE, Adamson U (1995) Day-to-day variation of insulin sensitivity in patients with type 1 diabetes: role of gender and menstrual cycle. Diabet Med 12:224-228

26. Bergman RN, Phillips LS, Cobelli C (1981) Physiologic evaluation of factors controlling glucose tolerance in man: measurement of insulin sensitivity and beta-cell glucose sensitivity from the response to intravenous glucose. J Clin Invest 68:1456-1467 